\title{
KESİNLİĞİN TEMELİ MÜMKÜN MÜDÜR?
}

Samet BÜYÜKADA*

\section{$\ddot{O Z Z}$}

Bilginin kesinliği sorunu klasik bilgi kuramı açısından oldukça incelenmiș bir meseledir. Bilgi için yapılan 'gerekçelenmiş doğru inanç' tanımını doğru tasdik olarak adlandıran Fârâbî, kesinliği (yakîn) ise hakkında inandiğımız şeyin dış dünyadaki varlı̆ı̆ın zihnimizde inandığımız șeyden farklı olmasının asla mümkün olamayacağına yönelik ikinci bir inanç olarak tanımlar. Fârâbî kesin olarak nitelendirdiğimiz bir bilginin nasıl ortaya çıktığına yönelik bir takım şartlardan bahsetse de bu durum, söz gelimi, tamamen rasyonel bir düşünce yapısına sahip iki farklı kișinin birbiri ile farklı doğruluk değerine sahip iki önermeyi temellendirmesine mani değildir. Öyle ki bu iki kişi dile getirdikleri önermenin kesin bilgi olduğunu iddia ettiklerinde aşılması zor bir durum ile karşılaşmış oluruz. Bu yazıda Fârâbînin bilgi ve kesinlik arasında kurduğu ilişsinin zeminine yönelik bir incelemeyi merkeze alarak Fârâbî'nin bilgi kuramı çerçevesinde bir yandan kesin bilginin bir temeli olabilir mi sorusuna yanit ararken diğer yandan bahsettiğimiz bu iki kişi Fârâbî ile karşslaşsaydı Fârâbî bu durumu nasıl çözümlerdi onu tartışacağım.

Anahtar Kelimeler: Kesinlik, kesin bilgi, temellendirme, Fârâbî, geleneksel mantık.

\section{IS THE GROUNDING OF CERTITUDE EVER POSSIBLE?}

\section{ABSTRACT}

The problem of certainty of knowledge is a rather studied issue in terms of classical epistemology. Al-Farabi, who refers to the definition of 'justified true belief' for knowledge as true assent, defines certainty (yaqîn) as a secondary belief that the existence of what we believe in the external world can never be different from what we believe in our minds. Although al-Farabi talks about some conditions regarding how a knowledge that we define as certain emerges, this situation does not prevent, for example, two different people with a completely rational mind from justifying two propositions with different truth values. When these two people claim that the proposition they utter is a certain knowledge, we are faced with a difficult situation to overcome. In this article, while searching for an answer to the question of whether there is a basis for certain knowledge as a part of al-Fârâbî's theory of knowledge, I will discuss how al-Fârâbî would have resolved this situation if these two people we mentioned had met with al-Fârâbî.

Keywords: Certainty, certain knowledge, justification, al-Fârâbî, traditional logic.

\footnotetext{
${ }^{*}$ Arş. Gör., İstanbul Medeniyet Üniversitesi, Felsefe Bölümü. busamet@gmail.com, ORCID: 0000-0003-0725-3396.

FLSF (Felsefe ve Sosyal Bilimler Dergisi)

2021 Güz, sayı: 32, ss. 195-204

Makalenin geliș tarihi: 27.04.2021

Makalenin kabul tarihi: 06.11.2021

Web: https://dergipark.org.tr/tr/pub/flsf
} 


\section{KESINLİĞİN TEMELİ MÜMKÜN MÜDÜR?}

Samet BÜYÜKADA

Bu yazıda Fârâbî'nin Kitâbu'l Burhân ve Şerâ'itul-Yakîn eserlerinde bahsi geçen kesinlik kavramından hareketle kesin bilginin temellendirilmesinin yapılıp yapılamayacağını tartışmayı amaçlıyorum. Bu tartışmaya geçmeden önce Fârâbî bilgi anlayışını açıklamak yerinde olacaktır. Fârâbî, bilgiyi tasavvur ve tasdik olmak üzere ikiye ayırır. Buna göre, eğer bilgi kavram düzeyinde ve olumlu ya da olumsuz bir hüküm bildirmiyorsa tasavvur; eğer en az iki tasavvur ve bunların arasındaki ilişkiyi belirleyen bir bağlaçtan/eklemden meydana gelen ifade ise tasdik adını almaktadır. ${ }^{1}$ Fârâbî'nin Kitâbu'l- Burhân ve Şerâitu'l- Yakîn eserlerinde bilgi ('ilm / episteme), kesinlik (yakîn/certitude) ve kesin bilgi (certain knowledge) kavramlarını zihin ve harici dünya arasındaki ilişkisi üzerinden ele aldığını görmekteyiz. Buna göre ilgili eserlerden hareketle birkaç tanımı vermemiz yerinde olacaktır:

[T1] Tasdik; [yargısal bilgi, propositional knowledge, assent] kişinin, bir mevzunun zihin haricindeki varlığının zihinde düşünülen varlı̆̆ ile aynı olduğu hükmüne inanmasıdır. ${ }^{2}$

[T2] Doğru tasdik, [doğru yargısal bilgi, true assent] konunun zihin dışındaki varlığının zihinde inanıldığı hali ile bulunmasıdır. ${ }^{3}$

[T3] Yakîn, [kesinlik, certitude] kendisine dair tasdikin meydana geldiği doğru hakkında şu şekilde inanmamızdır: 0 şey hakkında inandı̆̆ımız şeyin dış dünyadaki varlığının zihinde inandı̆̆ımız şeyden farklı olması asla mümkün olamayacağı gibi aynı zamanda bu inancın da bașka türlü olması mümkün değildir. ${ }^{4}$

Tasdikin gerçekleşebilmesi için kişinin yargı formunda (hüküm bildirmesi bakımından) dile getirilen bilgiye inanması gerekmektedir. Bu açıdan tasdik, sadece 'A, B'dir' gibi yargı bildiren önermeyi değil; aynı zamanda bu yargıya inanmayı da gerektirir ki Fârâbî bu durumu öznenin (bilgi) nesnesine yönelik bilinçli yönelimi olarak açıklar. ${ }^{5}$ Kısacası tasdik, bir mevzunun zihinde her nasılsa hariçte de öyle olduğuna yönelik bir inanç durumudur. İnanç da doğru ya da yanlış olabileceğinden, bu durumda, bir inancın olmadığı yerde tasdikten; doğru inancın olmadığı yerde de yakîni olmaktan söz edilemez

${ }^{1}$ Fârâbî, Kitabu'l-Burhan: Burhan Kitabı (İstanbul: Türkiye Yazma Eserler Kurumu, 2014), 15.

2 Fârâbî, Kitabu'l-Burhan, 15.

3 Fârâbî, SSera'itu'l-Yakîn, çev. Mübahat Türker Küyel (Ankara: Atatürk Kültür Merkezi Yayınları, 1990), 45 ve Fârâbî, Kitabu'l-Burhan, 15.

4 Fârâbî, Kitabu'l-Burhan, 17.

5 Fârâbî, Şera'itu'l-Yakîn, 47, 9. ve 15. satırları arasında ilmin manasının tartışıldığı bölüm. 
diyebiliriz. İnancın doğru olmasının koşulu ise bahse konu olan şeyin zihinde ve hariçte (dış dünyada) aynı olması gerekir. Bu durumun hakikaten böyle olması ise Fârâbî açısından doğru tasdik olarak adlandırılır. Bununla birlikte zihnimize konu olmasına ve ona inanmamıza rağmen hariçte karşıllı̆ı olmayan bir yargı ise tasdik olmasına rağmen yanlıştır. ${ }^{6}$ Buna karşın, eğer bir yargı dış dünyada bir gerçekliğe tekabül ediyor; ancak kişi buna inanmıyor ise, bu yargı doğru olsa dahi tasdik değildir.

Fârâbî̀nin yakîn kavramını doğru tasdik üzerinde geçekleşen ikinci bir inanç olarak tanımladığını görmekteyiz. Özturan konu ile ilgili makalesinde ikinci inancı, bir olgu ve durumun doğru olduğuna inanmayı birinci inanç olarak kabul ettiğimizde bu olgu ve durum dışındaki bir var oluşun imkânsız olduğuna inanmak olarak tanımlar. ${ }^{7}$ Bu açıdan, Fârâbî için yakîn kavramın anlaşılması, bu kavramın sıfat olarak başına geldiği kavramların her birinin tam olarak ne anlama geldiğinin açıklanmasıyla netliğe kavuşabilir. Fârâbî Kitâbu'l Burhân'da yakîni olmanın doğru tasdik ile olan ilişkisini ve tasdikin yakîni olup olmama durumlarını açılklamaya geçmeden önce yakîni olmayan tasdikin açılamasını verir. Yakîni olmayan tasdik; tasdik edilen şeyin inanca konu edilen varlı̆̆ına aykırı bir biçimde mümkün olduğuna veya imkansız olamayacağına inanmamızdır.8 Buna göre yakîn kendisine dair tasdikin hasıl olduğu doğru hakkında inandığımız şeyin varlığının, inandığımız şeyden farklı olmasının asla mümkün olamayacağına inanmamızdır. ${ }^{9}$ Kısacası, yakîn zihinde var olanın dış dünyada var olan ile asla bir çelişki içerisinde olamama durumu olarak izah edilmektedir. Bu öylesine bir durum olmalıdır ki onunla çelişecek herhangi bir bilginin doğru olması imkansızdır; aksi takdirde zaten bahsimize konu olan bilginin yakîni olması söz konusu dahi olamaz.

Şera'itu'l-Yakîn eserinin ilk paragrafında kesinliğin şartları yer alır. Buna göre kesin bilgi; (i) mutlak anlamda bir şeyin öyle olduğuna ya da olmadığına inanmaktır, (ii) onun dışarıdaki şeyin uygunluğunu kabul etmektir, (iii) bu uygunluğu bilmektir, (iv) onun aksinin olması mümkün değildir, (v) hiçbir vakitte onun aksinin olması mümkün değildir, (vi) bu şartlar ârızî değil zâtîdir. ${ }^{10}$ $\mathrm{Bu}$ şartları biraz daha sade bir biçimde Deborah Black'in ifadesi ile şöyle özetleyebiliriz:

i. $\quad S$, p'ye inanır.

${ }^{6}$ Mehmet Özturan, "Fârâbî̀ye göre bilginin kesinliği açısından yargısal bilgi türleri", İnsan \& Toplum 3, sy 5 (2013): 142.

7 Özturan, "Fârâbî", 138.

8 Fârâbî, Kitabu'l-Burhan, 16.

9 Özturan, Fârâbî, 147.

${ }^{10}$ Fârâbî, Şera'itu'l-Yakîn, 45. 

ii. $\quad p$ doğrudur.
iii. $\quad S$, $p^{\prime}$ nin doğru olduğunu bilir.
iv. $\quad p^{\prime}$ nin doğru olmaması imkansızdır
v. $\quad p^{\prime}$ nin yanış olabileceği bir vakit yoktur.
vi. $\quad$ i-v arasındaki şartlar özseldir, ilineksel değildir. ${ }^{11}$

Buna göre Fârâbî̀nin dile getirdiği kesin bilginin ilk üç koşulu bilginin geleneksel 'gerekçelendirilmiş doğru inanç' (justified true belief) tanımı ile örtüşmektedir. Sonraki üç koşul ise bu geleneksel tanımını daha da kuvvetlendirme amacı taşıyan sırasıyla, zorunluluk, ebedilik ve özsellik vurgusu taşımaktadır. Yine de bu altı şarta rağmen bir bilginin kesin olduğunu ya da o kesinliğin temelinin sarsılmaz bir şekilde sağlam olduğunu söyleyebilir miyiz? Şimdi Fârâbî’nin kesinlik üzerine görüşünün temeline ilişkin sorgulamamızın yöntemi üzerine bir fikir vermesi açısından, Suvar Köseraif in temellendirme hakkındaki yazısına kısaca bakalım.

\section{II}

Suvar Köseraif'in temellendirme üzerine yazısının ${ }^{12}$ ana düşüncesini kısaca şöyle açılayabiliriz: A ve B (tamamen rasyonel) kişileri bir konu hakkında birbirlerinden farklı bir düşünceye sahipler; A kişisi Q'ya inanırken, B kişisi de $\sim Q$ 'ya inanmaktadır. A kişisi B'yi ikna etmek için, 'P $\therefore$ Q' temellendirmesini öne sürüyor. B kişisi bu argümanın geçerli olduğunu kabul etmekle birlikte ' $\sim Q \therefore \sim P^{\prime}$ argümanının da geçerli olduğu sonucunu çıarıyor. B'nin kendisi zaten $\sim Q$ 'ya inandığı için, $\sim$ P'ye de inanıyor. Dolayısıyla B kişisi, Q'nun doğruluğu konusunda A'nın B'yi ikna etmek için öne sürdüğü $P$ önermesini, $Q$ önermesinin yanlış olduğuna inanmasından dolayı reddediyor. Diğer bir deyişle, 'P $\therefore Q$ ' temellendirmesine karşı ' $\sim Q$ ' önermesini savunan birisinin (modus tollens kuralı gereğince) ' $\sim \mathrm{P}$ ' önermesini de savunması gerekecektir. Bu durumda A kişisinin B kişini ikna etme çabası tam da B kişinin A kişisinin söyleminin aksini savunmasından dolayı boşa çıkacaktır. Köseraif'in burada dile getirdiği sorun, bir temellendirmenin gerekli (işlevli) olup olmadı̆̆ tartışması kadar, bir temellendirmeye konu olan öncüllerin doğruluk durumunun da sorgulanmaya açık olduğudur. Şimdi buradan hareketle Fârâbî'nin doğru tasdik ve yakîn kavramları hakkındaki düşüncesini irdeleyelim.

\footnotetext{
11 Deborah Black, "Knowledge ('ilm) and Certitude (yaqīn) in al-Fārābī's Epistemology", Arabic Sciences and Philosophy, 16, no. 1 (2006): 16.

12 Suvar Köseraif, "Felsefede Temellendirmenin İşe Yaramazlı̆̆ı: Bir Temellendirme Denemesi”, Felsefe Tartışmaları 23, 1998: 9.
} 
Q gibi dış dünyada karşıllığı olan bir önermemiz olsun. Bu önerme hakkındaki inancımızın da sarsılmaz bir şekilde doğru olduğunu varsayalım. Yani Q öyle bir önermedir ki onun yanlış olduğunu düşünen kimse yoktur; çünkü Q gerçekten de öyledir. Q hakkındaki ilk izlenimlerimiz şunlardır:

1. Q, herkes ona inandığı için doğru değil; doğru olduğu için herkes ona inaniyor.

2. Q'nun yanlış olduğunun düşünülmesi mümkün değildir.

Bu iki durumdan hareketle birisi bize 'Q'ya neden inanıorsun?' diye sorsa, ona karşı verilecek cevap gerekçelendirilmiş olmak zorundadır. Nitekim Q'ya onun Q olduğu için inandığımızı söylemek basit bir totoloji örneğidir ve bu sadece Q'ya duyulan güveni azaltır. Demek ki bir önermenin doğruluğuna dair 'ben Q'nun doğru olduğuna inanıyorum' söylemi Q'nun hakikaten öyle olması bir yana aynı zamanda bu inanca yönelik elimizde sağlam delillerin olmasını da gerektirir. Nitekim doğru tasdik, zihin ve dış dünya arasındaki mutabık olma ilişkisine yönelik bir inanç ise bu inancın temeli pekala sorgulanmaya açıktır.

Bu durumda şöyle diyebiliriz: 'Q'ya inanıyorum; çünkü onun gerekçesi olan P gibi bir önerme vardır.' Bir başka deyişle P önermesi Q'nun gerekçesidir. Dolayısıyla ben P önermesine de inanmak durumundayım; çünkü P önermesi benim en temelde inandığım önermenin dayanağıdır ve inanmadığım bir önermeyi temel olarak göstermem pek makul olmazdı.

$O$ halde şöyle bir biçimsel formül yazabiliriz: $(P \vdash Q)$

(PトQ) önermesi doğrudur çünkü P'nin doğru olduğu durumda hiçbir zaman Q yanlış olamaz ki Q'nun doğruluğundan şüphe yoktur. Benim Q'ya yönelik sarsılmaz inancım P ile desteklendiğine göre P'nin gerekçesi olduğu Q'den farklı bir R önermesinin olması da söz konusu olabilir. Hatta bu R önermesi de Q ile aynı epistemolojik şartları, Q'ya karşı duyduğum inancım ile aynı derecede doğru olması bakımından taşıyor olsun. $\mathrm{Bu}$ durumda $(\mathrm{P} \vdash \mathrm{R})$ gibi önermeyi de dile getirmek pekala mümkündür. Şimdi şunu varsayabilirim: Eğer Q'ya yönelik inancım sarsılmaz bir şekilde onun doğru olduğuna yönelikse, bu inancın kaynağı yanlış bir olgu olamaz; aksi takdirde $Q$, o kadar da sağlam bir önerme olmazdı. Ancak mantık dili bana aynı zamanda şunları söylüyor: $(P \vdash Q)$ argümanının geçerliliği sadece P önermesinin doğru olmasına değil P'nin doğru olduğu durumda Q'nun yanlış olmamasına bağlıdır. Varsaydığım durum bize şuraya sürüklüyor. Sarsılmaz bir şekilde doğru olduğuna inandığımız Q için bir gerekçe bulmak istediğimizde, $P$ gibi (Q'nun epistemik içeriği ile bağlantılı ya da bağlantısız olsun) bir önerme $(P \vdash Q)$ ifadesinin $Q$ 'dan kaynaklı doğru değeri 


\section{KESINLİĞİN TEMELİ MÜMKÜN MÜDÜR?}

Samet BÜYÜKADA

alması, Q'yu temellendirmede işlevsiz kalmaktadır. Yine de $P$ ve $Q$ arasında epistemik bir bağ olması temellendirmenin mantıklı bir yanı olduğuna yönelik inancımızı sağlamlaştırmaya yarayacaktır. Eğer $P$ önermesi yanlış ise $Q$ doğru olduğu sürece, ki onun doğru olduğunun şüphesiz olduğunu varsaymıştık, (P ト Q) geçerli olmaya devam edecektir. P'nin kendisinin yanlış olması ne Q'nun ne de $(P \vdash Q)$ epistemik içeriğinde bir değişikliğe sebep olmayacaktır.

Gerekçenin yanlış olması klasik mantıktaki ${ }^{13}$ yanlıştan her şey çıkar ilkesi (İng. principle of explosion; Lat. ex falso quodlibet) ile açıklanabilir. ${ }^{14}$ İlkeye göre bir çelişki öne sürüldüğünde, herhangi bir önerme ispatlanabilirdir: $(\mathrm{P} \wedge \sim \mathrm{P}) \rightarrow \mathrm{Q})$. Biçimsel aksiyomatik bir sistemde bir çelişkinin dolayısıyla da tutarsızlığın varlı̆̆ı istenmeyen bir durumdur; çünkü çelişkiden herhangi bir argüman kanıtlanabileceği için, doğruluk ve yanlışlık kavramlarını önemini yitirmektedir. Bu durumu aşmak için öne sürülen semantik delilin yeterli olmadığı kanaatindeyim. Nitekim semantik delile göre $Q$ önermeleri kümesinin her modeli P'nin de bir modeli ise P önermesi Q önermemeleri kümesinin semantik sonucudur. ( $\mathrm{P} \wedge \sim \mathrm{P})$ çelişik önermesi için bir model yoktur. Dolayısıyla

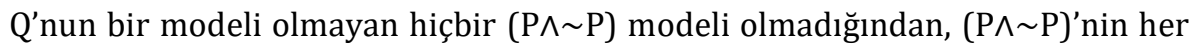
modeli Q'nun da bir modeli olacağı için $Q$ önermesi $(P \wedge \sim P)$ 'nin semantik sonucudur. Bir başka deyişle (P^ P)'nin doğru Q'nun yanlış olduğu bir model olmadığı için (P^ P)önermesi Q'yu mantıksal olarak gerektirmektedir. Açıkçası semantik sonuç ifadesi 'boș küme her kümenin alt kümesidir' söyleminden daha fazlasını vermediği gibi mevcut açıklamanın görünümünü kurtarmaktan daha öte bir yorum olduğu da söylenemez. Nitekim klasik mantığın bu yorumu bizim gerekçelendirmek istediğimiz önermenin temeline dair güçlü bir yorum yapmak bir kenara dursun, tersine tam da isminden anlaşılacağı üzere temelimizi patlamaya hazır bir şekilde bırakmıștır. Burada așılması gereken sorun, gerekçelendirmek istediğimiz önermenin yanlış öncüle sahip olmasının önüne nasıl geçileceğidir. (P^ P)'nin bir modeli olmadığı söylemini reddederek ona dair modeller geliştiren ya da çıkarımın kendisine itiraz ederek bize bir çözüm sunan tutarlı-ötesi mantıklar (paraconsistent logics) günümüzde bu sorunun aşılması için yardımcı olabilir.

Bir önermenin doğruluğu hakkındaki kesin bilginin, o önermenin çelişiğinin yanlış olduğu hakkındaki kesin bilgi olmaksızın hasıl olmasının mümkün olmadığını belirten ${ }^{15}$ Fârâbî̀nin açık bir biçimde yanlış bir önermeyi

13 Burada klasik mantık ile Aristotelesçi mantığa ișaret etmesi bakımından geleneksel (traditional) mantığı değil; İngilizcedeki classical logic kavramını kastediyoruz.

14 Carnielli, Walter, ve João Marcos, "Ex contradictione non sequitur quodlibet", Bulletin of Advanced Reasoning and Knowledge 1 (2001): 89.

15 Fârâbî, Şera'itu'l-Yakîn, 52. 
kesin bir bilginin temellendirmede kullanmasını beklemek fazla iyimser bir yorum olur. Bir önermenin çelişiğinin mutlak suretle yanlış olduğuna inanmak; yanlış olduğu bilenen bu önermenin yanlışlı̆̆ına inanmak demektir. Yanlışlığından şüphe edilmeyecek bir önermenin, doğruluğu hakkında şüpheye mahal bırakmayan bir önerme için dayanak oluşturması tuhaf bir durum olsa da yukarıda açıkladığımız yanlıştan her şey çıkar kuralı bunu mümkün kılmaktadır. Bir nesneye dair sebep bilinmek isteniyorsa, zorunlu olarak daha önceden bizde o nesnenin varlığına ilişkin bir bilginin olması gerektiğini söyleyen Fârâbî' ${ }^{16}$ mezkur ilkenin kullanımını kabul etmemesi halinde kendi düşüncesi içinde tutarlı kalmış olurdu. Nitekim, temellendirilmek istenen önermenin gerekçesinin bilinmesi ancak bu gerekçenin varlığının zorunlu olarak bilinmesi ile mümkün olmaktadır. Bunu çeliş̧inin varlığını bilmekten ziyade var olduğu bilinen bir durumun zorunluluğu olarak okursak bir anlam yakalayabiliriz.

Buraya kadar üzerine konuştuğumuz Q önermesinin Fârâbî̀nin kesinlik üzerine söylediği altı koşulu sağladığını var sayalım. Bu durumda iki seçenek karşımıza çıkar: Ya Q önermesini temellendirme çabası nafiledir ya da bu temellendirme öylesine akılcı bir yöntemle yapılmalıdır ki kesinliği üzerine tartışılmaz bir önermenin temelinin sağlamlığı kusursuz olsun. İlk seçeneği kabul etmek, aslında makul bir yöntemdir. Eğer ki Q önermesi bilhassa evrensel nitelikte bir genel geçerliğe sahip ise, zaten kendisi bir temele ihtiyaç duymayabilir. İkinci seçenek ise uğraștırıcı olduğu kadar aslında temellendirme yapmanın maksadını ortaya koyan bir yöntemdir. Ancak bu noktada Köseraif problemi aşılması zor bir engel olarak karşımıza çıkıyor. Fârâbî'nin kesinlik şartına karşı Köseraif şöyle bir açıklama sunsa idi Fârâbî’nin yanıtı ne olurdu?

\begin{tabular}{|c|c|c|c|}
\hline & A kișisi & & B kişisi \\
\hline $\begin{array}{l}\text { i. } \\
\text { ii. } \\
\text { iii. } \\
\text { iv. } \\
\text { v. }\end{array}$ & $\begin{array}{l}S, p^{\prime} \text { ye inanır. } \\
p \text { doğrudur. } \\
S, p^{\prime} \text { nin doğru olduğunu } \\
\text { bilir. } \\
\text { p'nin doğru olmaması } \\
\text { imkansızdır } \\
\text { p'nin yanış olabileceği } \\
\text { bir vakit yoktur. } \\
\text { i-v arasındaki şartlar } \\
\text { özseldir, ilineksel } \\
\text { değildir. }\end{array}$ & $\begin{array}{l}\text { i. } \\
\text { ii. } \\
\text { iii. }\end{array}$ & $\begin{array}{l}S, \sim p^{\prime} \text { ye inanı̆r. } \\
\sim p \text { doğrudur. } \\
S, \sim p^{\prime} \text { nin doğru } \\
\text { olduğunu bilir. } \\
\sim p^{\prime} \text { nin doğru olmaması } \\
\text { imkansızdır } \\
\sim p^{\prime} \text { nin yanış olabileceği } \\
\text { bir vakit yoktur. } \\
\text { i-v arasındaki şartlar } \\
\text { özseldir, ilineksel } \\
\text { değildir. }\end{array}$ \\
\hline
\end{tabular}

16 Fârâbî, Kitabu'l-Burhan, 29. 


\section{KESINLİĞİN TEMELİ MÜMKÜN MÜDÜR?}

Samet BÜYÜKADA

Bu tablo Fârâbî açısından kesinliğin şartlarının dördüncü maddesinin çelişki içermesi sebebiyle kabul edilmeyecektir. Yine de bu durum aynı konu üzerine farklı düşüncelere sahip kişilerin olamayacağı dolayısıyla da taban tabana zıt kesinlik iddiasının olamayacağı anlamına gelmemektedir. Fârâbî̀nin Kitâbu'l Burhân'da kesin bilginin kısımlarını açıkladığı bölüm Köseraif problemine karşı bir ölçüde çözüm sunuyor gözükmektedir:

Kesin bilgiler üç kısımdır: Bunlardan birincisi bir şeyin sadece varlı̆̆ına ilişkin kesinliktir ki bu varlık bilgisidir. İkincisi, bir şeyin sadece varlık sebebine ilişkin kesinliktir. Üçüncüsü ise her ikisine ilişkin kesinliktir (...) Açıktır ki bir nesnenin yalnızca sebebi bilinmek istendiğinde, zorunlu olarak daha önceden bizde o nesnenin varlı̆̆ına ilişkin bir bilgi olması gerekmektedir (...) 0 halde zorunlu kesinlik ile kurulan kıyaslar üç kısma ayrılır: Bunlardan biri, bizâtihî sadece bir şeyin varlığının bilgisini verir. İkincisi bizâtihî sadece sebebinin bilgisini verir. Üçüncüsü ise, bizâtihî hem varlığın hem de sebebin bilgisini verir. ${ }^{17}$

Fârâbî hem varlığa hem de sebebe ilişkin kesinliği mutlak olarak burhâni bilgi diye adlandırır. ${ }^{18}$ Buna göre mutlak burhân (ispat/demonstration) varlı̆̆ın hem bilgisini hem de sebebini veren burhândır ve burhân kendisinden elde edilen bilgilerin sebebidir. Burhâni klyas neticesinde $Q$ gibi bir önermeyi elde ettiğimizi söylersek bu önermeye ilişkin bilgi kesinlik taşıyacaktır. A ve B rasyonel kişilerinin geçerli bir burhâni kıyas karşısında ihtilafa düşmesi rasyonel düşünmeye ters düşeceği için B kişisinin savunduğu şeyin yanlış olduğuna ikna olmasını beklemek mümkündür. Yine de B kişisinin de $\sim Q$ önermesini burhâni bir kıyas neticesinde elde etmiş olması tümden imkansız değildir. Bu noktada Fârâbî'nin yapabileceği tek hamle iddia edilen kıyasın burhâni olup olmadığını incelemek olacaktır.

IV

Sonuç olarak Fârâbî̀nin kesinlik tanımının temeline ilişkin yürüttüğümüz sorgulamada Köseraif'in temellendirmenin temeline ilişkin öne sürdüğü problemin tamamen aşılamadığı kanaatindeyiz. Fârâbî için A ve B rasyonel kişilerinin savunduğu biçimde birbiri ile çelişik bir önermenin dış dünyadaki mevcudiyeti her ne kadar kabul edilebilir olmasa da kesinliğin nasıl

17 Fârâbî, Kitabu'l-Burhan, 27-28.

18 Fârâbî, Kitabu'l-Burhan, 28. 
temellendirileceği sorunu mevcudiyetini korumaktadır. Doğruluğu şüphe götürmeyen bir önermenin, eğer öyle bir önerme varsa tabi ki, niçin temellendirilmek istendiği sorulabilir. Bunun en basit yanıtının sağlamlık için olduğunu söyleyebiliriz. Öyle görülüyor ki doğru olduğuna inandığımız P gibi bir önermenin temellendirmesi istediğimiz sağlamlıkta pek mümkün olmasa da onun sadece doğruluğa inanmak pek yeterli değildir. Kesinliğin gerekçesi, en azından, önerme ile ilişkisi bağlamında onunla alakadar önermelerle sağlandığı takdirde güçlü bir temellendirme yapılabilir. Bu bize en azından temelsiz kalmaktansa zayıf da olsa bir temel sağlayacaktır. Fârâbî için bunu sağlayan yöntemin adı burhâni kıyastır. Farklı öncüllerle kurulu iki burhâni kıyas birbiri ile çelişen iki önerme ile sonuçlansa dahi bu önermelerin hem zihinde hem de dış dünyada aynı anda bulunmaları mümkün değildir. 
KESINLİĞİN TEMELİ MÜMKÜN MÜDÜR?

Samet BÜYÜKADA

\section{KAYNAKÇA}

Black, Deborah. "Knowledge ('ilm) and Certitude (yaqīn) in al-Fārābī's Epistemology", Arabic Sciences and Philosophy, 16, no. 1 (2006): 11-46.

Fârâbî, Kitabu'l-Burhan: Burhan Kitabı. (İstanbul, Türkiye Yazma Eserler Kurumu, 2014).

———. Şera'itu'l-Yakîn, Çev. Mübahat Türker Küyel. (Ankara: Atatürk Kültür Merkezi Yayınları, 1990).

Köseraif, Suvar. "Felsefede Temellendirmenin İşe Yaramazlı̆̆ı: Bir Temellendirme Denemesi”, Felsefe Tartışmaları 23 (1998): 9.

Özturan, Mehmet, "Fârâbî̀ye Göre Bilginin Kesinliği Açısından Yargısal Bilgi Türleri”, İnsan \& Toplum 3, sy 5 (2013): 135-158.

Walter, Carnielli ve João Marcos, "Ex contradictione non sequitur quodlibet". Bulletin of Advanced Reasoning and Knowledge 1 (2001): 89109. 